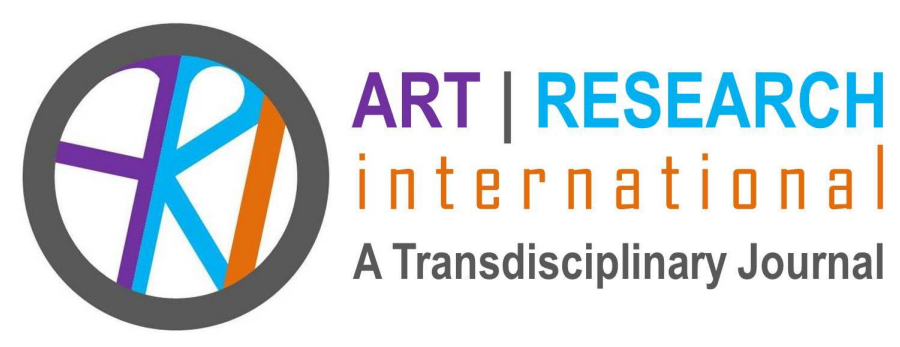

\title{
EDITORIAL
}

\section{VOLUME 5, ISSUE 1}

\section{ENCOUNTERING ARTISTIC RESEARCH PRACTICES: ANALYZING THEIR CRITICAL SOCIAL POTENTIALITIES}

\author{
Karin Hannes \\ Research Group SoMeTHin'K \\ (Social, Methodological and Theoretical Innovation/Kreative), \\ KU Leuven, Belgium \\ karin.hannes@kuleuven.be
}

Rudi Laermans Theory, Culture and Religion Research Group, KU Leuven, Belgium* rudi.laermans@kuleuven.be

*Joined lead authors

Karin Hannes coordinates research group SoMeTHin'k (Social, Methodological \& Theoretical Innovation with a creative twist) at the Faculty of Social Sciences, KU Leuven and specializes in arts-based, place-based, multisensory and futuring research designs as well as qualitative evidence synthesis as a meta-review technique. Prof. Hannes works from an inclusive, academic activism perspective actively pushes towards the development of methods and models for positive change in society. Her perspective is transdisciplinary and multimodal in nature, combining numerical, textual, sensory and/or arts-based research d.a.t.a to study complex social phenomena. 
Rudi Laermans is senior professor of Social Theory and Sociology of the Arts at the Faculty of Social Sciences, KU Leuven. His theoretical research focuses on the founders of sociology (Max Weber, Emile Durkheim), contemporary social systems theory (Niklas Luhmann) and contemporary critical theory (Michel Foucault, Giorgio Agamben, Autonomous Marxism). This multi-faceted theoretical interest also inspires his interdisciplinary interest in the arts, particularly the field of contemporary dance. 
Attempting to categorize the most important trend within the field of the then fine arts, French art critic and curator Nicolas Bourriaud (2002) coined the notion of "relational aesthetics" or "relational art." The expression refers to a multiple set of artistical practices "which take as their theoretical and practical point of departure the whole of human relations and their social context" (p. 113). Claire Bishop (2006) saw this trend confirmed in the following years and in 2006, in an influential essay in Artforum International, launched the idea of a broader social turn in the visual arts. The focus on different modes of collaboration with a variety of publics would no longer characterize a specific artistic segment, but rather form the dominant trend in art/ research practice.

The social turn also deeply affected the various performing arts, including theatre (see for instance Jackson, 2011; Malzacher, 2015), dance (Laermans, 2015), and music (Colin \& Sachsenmaier, 2016). A wide range of working forms, methods or practices is involved, varying from participatory art still framed by a semi-directive approach over more symmetrically informed community art projects to outright activist art that acts in tandem with broader protest movements (Kester, 2011). What binds these socially engaged and often research-embedded artistic projects is their encountering element, with the artworks produced holding equal (in many cases less) importance to the collaborative act of creating them and the interaction involved in doing so (Finkelpearl, 2013).

Most social art is guided by a critical perspective on power inequalities and their effects within the spheres of for instance gender, ethnic majorities-minorities relationships, the economy, or the daily lifeworld as impacted by environmental changes. Together with raising awareness concerning social justice and equality, direct individual empowerment and collective emancipation are often explicit goals of social art. Artists involved in the corresponding practices tend to use art as a vehicle to engage with the texture of social life, eventually disrupting the seemingly natural flow of the social in order to stimulate reflection and invite action for change.

Notwithstanding the variety of deployed modes or methods, social art has some marked features distinguishing it from the modernist stress on art's autonomy. First, the emphasis is on social processes or dynamics; hence, social art practices emphasize immaterial social dynamics rather than the production of aesthetic objects. Second, social art cultivates a critical approach that goes against the commercial grain of the visual arts world in particular. Hence, the related practices opt for a de-commodified creativity short-circuiting art markets. Third, the construction and reconstruction of social relationships may take place in a gallery or museum context or within the more specific established frameworks corresponding with the genres of theatre, dance, or music performance. However, there is a definite preference not to work in the white cube or 
the black box and to experiment with existing or new emancipatory modes of sociability within public space (Bax, Gielen, \& leven, 2016; Meier \& Frers, 2016). This is linked to an anti-elitist stance and the will to reach out to social groups, or even collectives-yet-tobe-defined, that are likely to be negated by art institutions (Kester, 2011). Fourth, the process-identity of socially engaged artistic practices implies the possibility to use joined creation for imagining new identities or to transform disruptive habits of minds evoked by personal, structural, or life changing events shared with significant others. A fifth and last key characteristic concerns the notion of "social" in the expression "social art." Given that it is nearly always made for a public, however small, art has per definition a social rationale. Yet practices exemplifying the idea of social art emphasize participation, dialogue, co-action or co-creation. As such, they subvert the traditional notion of authorship and seem to ask for concepts such as multiple authorship. Besides being multiple, authorship constantly shifts within collaborative artistic practices, which precludes naming a final creator. Indeed, the created work is the outcome of a nonlinear work of encountering encompassing moments of explicit negotiation as well of periods of social improvisation. In order to underline this open and dialogical character of social art, we choose to speak of encountering artistic practices.

Making encountering art may not just be a way to create art with a high social value. In many instances, this endeavor is intrinsically linked with an outspoken research interest. Precisely because of their open social dynamics, encountering artistic practices can shed light in an innovative way on the different social textures that may emerge in relation to different modes of encountering (Wang, Coemans, Siegesmund, \& Hannes, 2017; Cahnmann-Taylor \& Siegesmund, 2017). Such a research interest includes a focus on the underlying dynamics through which artistic practices either reenforce or re-define general notions of "differing" and how they either challenge existing societal power mechanisms or alternatively keep them into place (Beyes \& Steyaert, 2011; McDowell, 2018).

Furthering social enlightenment or empowerment, and investigating existing or, especially, potential emancipatory modes of sociality through encountering artistic practices may be indeed two sides of one and the same coin. This requires new notions of how to study socially engaged research practices. Not all encountering art also testifies of a research attitude or is informed by a premeditated methodology and a wellconsidered theoretical framework. Thus, many examples of straightforward activist art consider effective social change as more important than an interest in how this may be reached through a research informed encountering artistic practice. The evident danger of this kind of artistic activism is that the process of encountering is instrumentalized to such an extent that the intrinsic socio-political value of that very process is no longer recognized. 
There are yet more direct, non-political modes of instrumentalization, even of commodification. When organized within the confining walls or under direct impulse of art institutions, encountering artistic practices may risk becoming collaborative in a negative sense, i.e. to contribute to the public attractivity of a museum or theater without much critical effect. Against their critical grain, encountering events can indeed be "just fun," preach to the already converted cultural bourgeoisie, or anything but heighten the sense for social change because an overtly moral stance sits in the way of genuine political claims (compare Bishop, 2012).

When assembling this special issue, we wanted to foster the already rich dialogue between encountering art and research-based art. The material and immaterial dimensions created during social encounters are not solely an expression of what has been found. Artistically inspired processes work performatively. Hence in their expression, the artworks become the research itself (Haseman, 2006). Given the just mentioned potential pitfalls of the first, we were particularly interested in examples of artistic research practices creating encounters between people and the public domain that have a clear critical edge, embrace the power of critical dialogue and enhance the common good.

Specific lines of interest for our call included non-intentional "nomadic" encounters in public space, as addressed by practices ranging from public art to creative activism (Braidotti, 2011), community framed encounters as addressed by community and co-creative art projects (Jackson, 2011), and audience based encounters resting on a shared time and physical attention as addressed by live and performing arts (Malzacher, 2015).

The contributions to this special issue further our understanding of the impact of the blurred lines between art, social life, and scholarship as illustrated by encountering art. Several authors critically challenge our current understanding of what art can achieve or is supposed to provide in social terms; still others question the idea that artistic practices should necessarily be perceived as a means to a social end. More generally, all contributions go beyond the all too simple and questionable impact approach of the use of art in widening audience participation or transforming participants and communities. The studies we included testify of a reflexive attitude informed by the kind of intellectual curiosity as well as awareness of potential limits informing all genuine artistically inspired research. Moreover, several papers relate the discussed case to broader issues by situating them in an economic, cultural, educational, social and/or political context.

In the Theoretical Musings section, Maureen Flint uses Rosi Braidotti's concept "nomadic ethics" in relation to the process of making paper and develops new 
considerations on ethics and representation in research methodology and art through social encounters with a broader public. Nerina Jane Caltabiano investigates the concept of liminality defined as a phase of change, transition, and transformation from a social justice perspective. Rather than limiting the work to the study of how artworks may soothe childhood trauma, it is situated in the broader context of "professionalism for sustainable societal change." Lynn Sanders-Bustle takes a methodological stance, explaining how qualities associated with social practice overlap with and extend existing arts-based research practices. She presents the work of three socially engaged artists wherein the emphasis is not on art as an object but rather on the alternative social exchanges that emerge through participation with others. Shannon Forrestor engages with the dynamics of exclusion through reparative painting and considers how systemic cultural agents deploy inequity to obstruct human flourishing.

The Art/Research in Action section presents eight case studies written by authors with a variety of different backgrounds. Enni Mikonen and colleagues present a participatory theatre project with immigrant women to investigate how art-based research can function as a decolonizing research method. Its analysis is based on the combination of social work and art education disciplines for advancing social justice and deconstructing power dominances. Davina Kirkpatrick embarks on a polylogue in which a collaborative shared experience of loss is environmentally materialized. She argues that "absence" has agency and can be located in a shared space. Justin Langois uses the concept of antagonism as a guiding principle for his artwork. He situates the idea of conflict in the broader context of social democracy, explaining how artists may deploy disagreement against larger hegemonic structures and help foster new expressions of agency. Kelly Clark/Keefe's "Life Lines" project is an example of a critical participatory arts-engaged research endeavor aimed at opening up conventional theoretical wisdom about the nature of young adult college students identity formation. She uses a multiplicity of expressive forms to challenge identity development models that limit subjectivity to human consciousness and agency in the absence of acknowledging somatically attuned sets of practices and productions. Heike Langsdorf and Ernst Marechal invite us into reconsidering authorship practices, focusing on the idea that what is overwritten through communal and multi-perspective experience is always more promising (however, not necessarily better!) than what vanished the moment when it mismatched our individual ideas. They illustrate this convincingly in the dialogue they have built with each other. Time to invite our readers into "encountering" art/science research practice. 


\section{REFERENCES}

Bax, S., Gielen, P. \& leven, B. (Eds.) (2016). Interrupting the city: Artistic constitutions of the public sphere. Amsterdam, NL: Valiz.

Beyes, T., \& Steyaert, C. (2011). The ontological politics of artistic interventions: Implications for performing action research. Action Research, 9(1), 100-115.

Bishop, C. (2006). The social turn: Collaboration and its discontents. Artforum International, 44(6), 178-183.

Bishop, C. (2012). Artificial hells: Participatory art and the politics of spectatorship. London: Verso, 2012.

Bourrdiaud, N. (2002). Relational Aesthetics. Dijon: Les presses du reel.

Braidotti, R. (2011). Nomadic theory: The portable Rosi Braidotti. New York: Columbia University Press.

Cahnmann-Taylor, M., \& Siegesmund, R. (Eds.). (2017). Arts-based research in education: Foundations for practice. New York: Routledge.

Colin, N., \& Sachsenmaier, R. (Eds.) (2016). Collaboration in Performance Practice. New York: Palgrave.

Finkelpearl, T. (2013). What we made: Conversations on art and social cooperation. Duke University Press.

Haseman, B. (2006). A manifesto for performative research. Media International Australia incorporating Culture and Policy, 118(1), 98-106.

Jackson, S. (2011). Social works: Performing art, supporting publics. New York: Routledge.

Kester, G.H. (2011). The one and the many: Contemporary collaborative art in a global context. Durham, NC: Duke University Press.

Laermans, R. (2015). Moving Together. Theorizing and Making Contemporary Dance. Amsterdam: Valiz. 
Malzacher, F. (2015), Not just a mirror. Looking for the political theatre of today. Berlin, DE: Alexander Verlag.

McDowell, L. (2018). Gender, identity and place: Understanding feminist geographies. New Jersey, NY: John Wiley \& Sons.

Meier, L., \& Frers, L. (2016). Encountering urban places-Visual and material performances in the city. In L. Meier \& L. Frers (Eds.), Encountering urban places: Visual and Material performances in the city (pp. 17-24). Routledge.

Wang, Q., Coemans, S., Siegesmund, R., \& Hannes, K. (2017). Arts-based methods in socially engaged research practice: A classification framework. Art/Research International: A Transdisciplinary Journal, 2(2), 5-39. 